\title{
Completion of the sequence of the Aspergillus fumigatus partitivirus 1 genome
}

\author{
Charalampos Filippou $^{1} \cdot$ Robert H. A. Coutts $^{1} \cdot$ David A. Stevens $^{2,3} \cdot$ Raquel Sabino $^{4} \cdot$ Ioly Kotta-Loizou ${ }^{5} \odot$
}

Received: 5 January 2020 / Accepted: 12 April 2020 / Published online: 27 May 2020

(c) The Author(s) 2020

\begin{abstract}
A Portuguese isolate of Aspergillus fumigatus was found to contain three double-stranded (ds) RNA elements ranging in size from 1.1 to $1.8 \mathrm{kbp}$ and comprising the genome of a strain of Aspergillus fumigatus partitivirus 1 (AfuPV-1) previously thought to contain only the two largest dsRNA elements. The sequence of the smallest dsRNA element is described here, completing the sequence of the AfuPV-1 genome. Sequence analysis of the element revealed an open reading frame encoding a protein of unknown function similar in size and distantly related to elements previously identified in other members of the family Partitiviridae.
\end{abstract}

Mycoviruses are widespread in almost all major groups of fungi, and most cause no obvious effects in their hosts, but some do cause obvious symptoms resulting in debilitated virulence, slow growth rate, and poor sporulation [5, 8]. Currently recognized mycoviruses have single-stranded (ss) or double-stranded (ds) RNA, or rarely DNA, as their genetic material [8]. Members of one family, the Partitiviridae, are classified into five genera, namely Alphapartitivirus, Betapartitivirus, Gammapartitivirus, Deltapartitivirus and Cryspovirus [17]. Partitiviruses generally possess two essential dsRNA genome segments (1.3-2.5 kbp in length), each containing a single open reading frame (ORF) [17]. The larger component 1 encodes an RNA-dependent RNA

Handling Editor: Massimo Turina.

Ioly Kotta-Loizou

i.kotta-loizou13@imperial.ac.uk

1 Department of Biological and Environmental Sciences, School of Life and Medical Sciences, University of Hertfordshire, Hatfield, UK

2 Division of Infectious Diseases and Geographic Medicine, Stanford University School of Medicine, Stanford, California, USA

3 California Institute for Medical Research, San Jose, California, USA

4 Infectious Diseases Department, National Institute of Health Dr. Ricardo Jorge, Lisbon, Portugal

5 Department of Life Sciences, Faculty of Natural Sciences, Imperial College London, London, UK polymerase (RdRP), and the smaller component 2 encodes the capsid protein (CP) [17]. On occasion, smaller dsRNAs than the two dsRNAs described above encoding proteins of unknown function have been reported for some partitiviruses. Examples include Ustilaginoidea virens partitivirus 1 (UvPV-1) [18], Gremmeniella abietina RNA viruses MS1, MS2 and MS3 (GaRV-MS1, -MS2 and -MS3) [3, 15, 16], Aspergillus ochraceous virus (AoV) $[10,11]$ and Aspergillus flavus partitivirus 1 (AfPV-1) [6], but not Aspergillus fumigatus partitivirus 1 (AfuPV-1) [2] or a second isolate of UvPV [7]. During our continued monitoring of the incidence of mycoviruses in Aspergillus fumigatus, an opportunistic pathogen causing aspergillosis in the immunocompromised human population, we isolated, cloned and sequenced a Portuguese strain of AfuPV-1 termed AfuPV-1A. An examination of the dsRNA profile of AfuPV-1A revealed that it contained three dsRNA components, with the sequences of the two largest dsRNAs being $98-99 \%$ identical to those of AfuPV-1. These results confirmed that AfuPV-1A is a strain of AfuPV-1 that can support the replication of a third genomic component termed dsRNA3 and that smaller dsRNA components can apparently be lost and recovered during partitivirus infections. Here, the sequence of the AfuPV-1A dsRNA3 element is reported, completing the sequence of the AfuPV-1A genome. Additionally, relationships between AfuPV-1A dsRNA3 and AfuPV-1 dsRNAs 1 and 2 were investigated together with comparisons to other small dsRNA elements of partitiviruses. 
(a)

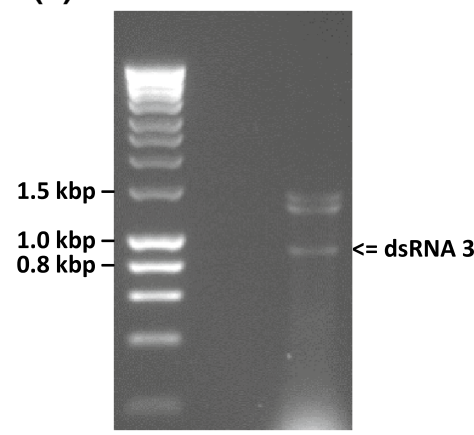

(b)

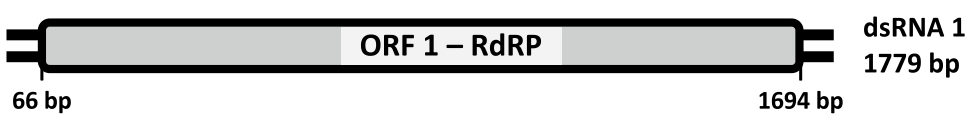

(c)

\begin{tabular}{|c|c|c|c|c|}
\hline fuPV-1 & 1 & ---------------- MCKSNS- & ---EAASLTKRSSR-LPSVFNHGKAAKCRLNRCGVRHAPK & 42 \\
\hline UVPV-1 & 1 & $--------------M V C F P Q S G[29$ & ] SLRVNA- [ 5] VKTEAAALQKCSYHPSPRGAGEGKGKKKYHSKRKLKSAAV & 88 \\
\hline aRV-MS1 & 1 & $-----------------M S K T Q T N$ & ----------------------------PPKPKGKIRQPS- & 6 \\
\hline VAPV -2 & 1 & MNKLKIEDVSPSKDTRAGSPPSIGE [ 28 & ] LESEIARLSKEQQKKFQQLVRKQSGSKEPRGRSPRKSKSP & 20 \\
\hline oV & 1 & IGKNDEDCGPLTPQYLLSRKRYGE & --------------------------- PLHPRGI & 15 \\
\hline JAPV -10 & 1 & ---NDTKMSSRERRLSDISSSGSK & NTLVDER [ 6] ACGRKGRFGCGTSYMCPRTKRPSRGPKPTSPRR: & 5 \\
\hline $\begin{array}{l}\mathrm{EuPV}-1 \\
j \mathrm{PV}-1\end{array}$ & $\begin{array}{l}43 \\
89\end{array}$ & $\begin{array}{l}\text { LEQRFKTAFSKALAVRSRVL } \\
\text { - QLKFRRAFSKALVVRTRVL }\end{array}$ & $\begin{array}{l}\text { GRRLTREEWVKLKHAVRYQCFGPTVP-LQKQLTMLATRVARCE } \\
\text { GRRLHRKECVALKVAVRKQVFASKADEATRILTQVRAEVARLF }\end{array}$ & \\
\hline -MS1 & 27 & ---RFKKALARALSVRSKFL & KRRLSKPEFVQLSAAVKTQIKQETTP-VNRRLNRVIDIVVRLEEA & 98 \\
\hline VAPV -2 & 121 & EQERFQRAIRKASSVRRRQL & GRELEHDEWIQLRNAVRKQCSNVKTDDFTKRLSVLETRLSRLESGTYASDPG & 36 \\
\hline $\mathrm{OV}$ & 46 & --- RFDKAFRKAIAIRVRVL & GRPLTQLEFRRLVSAVRKQIQPRLENFVSRAVMNIEKRVKTLELATPTSVA- & 117 \\
\hline VAPV-10 & 76 & $\begin{aligned} \text { KQQK [ 22] DDDRVSSAIRKSYRVRCLSL } \\
$\[ : \quad *:: \quad: *{ }^{*} * \]$\end{aligned}$ & 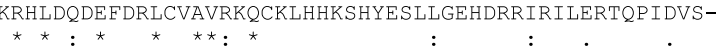 & 172 \\
\hline 1 & 116 & S---SVADS IELMYQQLSLLRAQAMELM & SERES IA-PSCPHFRKRKVFPTPSNQLQIGV--KPLGWHSVITYRLQGRDET & 9 \\
\hline $\mathrm{VPV}-1$ & 162 & L---QASDSVQILNLQLSVLRQQFMELV & SSDNS-T-ETCPHYRKRKVYRAPNSDGSFHF--QVPGLSELIVWQPRGQVEQ & 234 \\
\hline GaRT & 99 & DRPALDAAVRNLYDRLNLVRSNLLEAM & RESSSLS-EGCSHVSKKSVIHLPEPVKVDKI---FPGFGCI-SVRIPSGRQV & 173 \\
\hline PAPV -2 & 197 & V---QIADKISIFQLQLDIARRQMLELI & NDQASIS-EGCSHLAKKVVIKTVEPFEV-----QIKGPGIVGYCN & 267 \\
\hline $\mathrm{A} \circ \mathrm{V}$ & 118 & ----QLESAIAMFHTQVTVLREQAMRAI & QENDVLS-ETCSH ISHKKM--LPVPTDMERLTAHFPNLGHL-TISLKP-TEV & 88 \\
\hline PVAPV-10 & 173 & $\begin{array}{c}---A L Q D A I E N T Y S Q L E V L R T Q L L N A I \\
.\end{array}$ & $\begin{array}{l}\text { QDQEENSLPSCTHMKHQINVRNSERFQIEHL---IPSFGLI-FHHFSPTSLR } \\
0_{*}{ }_{*} .\end{array}$ & 244 \\
\hline & & $:: \quad: \quad: \quad: \quad:$ & *.* : : & \\
\hline & 190 & LCCGACLQARSDAWFSWTGEELRFEHFL & SAISP-LSIQGIWSQILLQKYGSDFS [ 1] & 25 \\
\hline & 235 & CCPSCLSDREDTFFTWTGELPPQFSLS & KGEMDPVIS---PSERAL & \\
\hline GaRV-MS1 & 174 & LCCSRCSGLRNDAFFEWSGLQ-PSFIDK & KNINP-LDFQHVWTSVLDVHYSR--- & 37 \\
\hline PVAPV-2 & 268 & SCCDRCLSDRRDFIFESLGLETSPF--R & AGDSIDSVDH---LNTTL [10] EGVDP-MRFQHIWSLFLDKKFGR--- & 40 \\
\hline $\mathrm{A} \circ \mathrm{V}$ & 189 & LCCDSCLAKRQDSVFLWSGVDLVSLADM & SQVHP-LSIQSIWTAVVNLKYDRTFQ [34] & 293 \\
\hline VAPV -10 & 245 & LACGKCIQKREDILFYWTGHQLPKFSSI & KEVSP-LAVPQIWNQVLDLKYDREI- & 306 \\
\hline
\end{tabular}

(d)

$5^{\prime}-$ UTRS

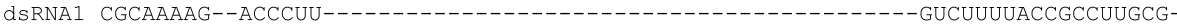

dSRNA2 CGCAAAAGGAACCCUUUUGACUCCAGUGUAUCUGGAGGGUUUACGCUAAARUUUAUAAAACCGUAAACUAAAUUAUL

dsRNA3 CGAAAAUU--UUCCUCUCUCCCUGAGGGGGUGGGAUGAGAAUGUAGGAAAUUUUCCUAGGUGUUCAAGUGUUUUAUAUAGACACUGGCCG

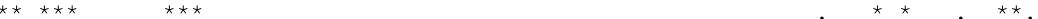

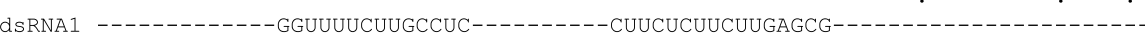

dsRNA2 --------------UCCUCGAGCCUC----------CUUCUCU----AAGCG--

dSRNA1 --

dSRNA2 -- - -

dsRNA3 ACUCGCUCGGUUUCUUGGCCCUGGUUAUUGAGAACUUAUUCUAC

3'-UTRS

dSRNA1

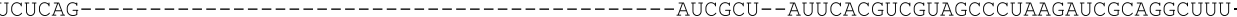
dsRNA2 ACAUAGCCAGUACUUGAAGAAACCAGUUUAUCUGGUCAAGCCCAACCUUACCACUAGAUGUCUGGCCGUUUAUCGGUAGCGCUAGUGUUG

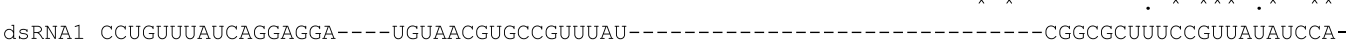

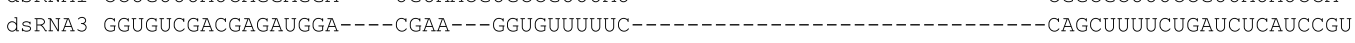
dsRNA2 CCUGUCUAUCAGGAAGACCCGUGUAUCGGGCCAUCUAUUUCCUAUCAAGGAGGUGGGUGAUAACGUGGCCGUUUAUCGGUACGUGUUCAC

$$
\star \star \star * \star * . . * *
$$

dsRNA1 --------------

dSRNA3 CCCAAAUGAGAUCCGU

dSRNA2 UGUAAAUCCA------ 
4Fig. 1 Genomic organisation of AfuPV-1 and comparisons of the amino acid sequences of putative proteins encoded by dsRNA3 elements of representative partitiviruses. (a) Agarose gel electrophoresis of dsRNA elements extracted from A. fumigatus isolate 12/43 Molecular sizes are indicated on the left with numbers. (b) Schematic representation of the genome organisation of AfuPV-1A. AfuPV-1 dsRNAs 1, 2 and 3 each contain a single ORF (grey boxes) flanked by 5'- and 3'-UTRs (black lines). The dsRNA1 is 1779 bp long and contains an ORF that encodes a putative RdRp with a molecular mass $(\mathrm{Mr})$ of $63 \mathrm{kDa}$. The dsRNA2 is $1623 \mathrm{bp}$ long and contains an ORF that encodes a putative $\mathrm{CP}$ with a $\mathrm{Mr}$ of $48 \mathrm{kDa}$. The dsRNA3 is 1112 bp long and contains an ORF that encodes a protein of unknown function with a $\mathrm{Mr}$ of $29 \mathrm{kDa}$. (c) BLAST COBALT alignment of the amino acid sequences of the putative proteins of unknown function encoded by the smallest genomic dsRNA3 elements of Aspergillus fumigatus partitivirus-1A (AfuPV-1A; LR743535), Ustilaginoidea virens partitivirus 1 (UvPV-1; AGO04405), Gremmeniella abietina RNA virus-MS1 (GaRV-MS1; AII16003), Plasmopara viticola associated partitivirus 2 (PvAPV-2; QHD64806), Aspergillus ochraceous virus (AoV; AYP71820) and Plasmopara viticola associated partitivirus 10 (PvAPV-10; QHD64798). Accession numbers are shown in brackets above. In the sequence alignment, asterisks signify identical amino acid residues, colons signify highly conserved residues, and single dots signify less-conserved but related residues. (d) Alignment of the 5'- and 3'-UTRs of the coding strands of the three genomic segments of AfuPV-1A, where asterisks indicate identical nucleotides in the three elements and single dots signify conserved purines or pyrimidines

\section{Provenance of the virus material}

A. fumigatus $12-43$ was originally isolated from bronchial secretions of a hospitalised patient in Portugal [12]. This was the only A. fumigatus isolate found to harbor dsRNA elements following the screening of 48 isolates in total: 12 environmental, 12 avian, 12 from cystic fibrosis patients, and 12 , including isolate 12-43, from non-cystic fibrosis patients [12-14]. The A. fumigatus isolate $12-43$ was grown in liquid Czapek-Dox complete medium at $25{ }^{\circ} \mathrm{C}$ with shaking. Purification of virus particles was performed as described previously [9], and dsRNA was extracted from the particles using phenol/Sevag treatment. Three viral dsRNA elements were separated by electrophoresis on a $1 \%(\mathrm{w} / \mathrm{v})$ agarose gel containing Tris-acetate-EDTA (TAE) buffer and $500 \mathrm{ng}$ of ethidium bromide per ml (Fig. 1a). The two larger dsRNAs 1 and 2 of the A. fumigatus isolate 12-43 were 1779 and 1623 bp in size, respectively, and were $99 \%$ and $98 \%$ identical in sequence to those previously reported to constitute the genome of AfuPV-1 [2]. The additional smaller dsRNA is referred to as "AfuPV-1A dsRNA3" in this study. AfuPV1A dsRNA3 was extracted from the gel using a MinElute Gel Extraction Kit (QIAGEN) and its dsRNA nature was confirmed by its resistance to DNase 1 and S1 nuclease (Promega). Subsequently, the dsRNA was denatured with methyl mercuric hydroxide, and this served as a template for reverse transcription and PCR amplification using random primers [5]. The sequence was completed using sequence specific primers, genome walking, and RNA ligase-mediated rapid amplification of cDNA ends [4]. All products were cloned using the pGEM-T Easy Vector system (Promega) and introduced into competent Escherichia coli XL10-Gold cells (Agilent). At least three different clones covering the same part of the genome were sequenced. The effects of AfuPV-1A on the phenotype and pathogenicity of its host are currently unknown but are assumed to be similar to those described previously by Bhatti et al. [2] who observed an abnormal colony phenotype, slow growth, and lighter-thannormal pigmentation.

\section{Sequence properties}

AfuPV-1A dsRNA3 is 1112 bp in length, has 50\% GC content and possesses a single ORF that encodes a hypothetical protein of unknown function comprising 258 amino acids (aa) with a molecular mass of $29.274 \mathrm{kDa}$ (Fig. 1b). A BLASTp [1] search using the non-redundant protein sequences database updated on 6 April 2020 revealed that the amino acid sequence of the protein encoded by the AfuPV-1A dsRNA3 ORF was $41.5 \%, 32.6 \%$ and $31.5 \%$ identical to that of the corresponding protein of unknown function encoded by the smallest genomic dsRNA3 elements of UvPV-1 (303 aa), AoV (293 aa) and GaRV-MS1 (237 aa), respectively. It also demonstrated $33.2 \%$ and $30.3 \%$ sequence identity to dsRNA3 of the recently reported Plasmopara viticola associated partitivirus 2 (PvAPV-2; 340 aa) and Plasmopara viticola associated partitivirus 10 (PvAPV10; 306 aa), respectively (Fig. 1c). Neither GaRV-MS2 nor GaRV-MS3 was included in these alignments, as they are considered to be strains of GaRV-MS1 [3, 16]. The AfuPV1A dsRNA3 ORF is flanked by 5'- and 3'-UTRs 222 and $113 \mathrm{bp}$ in length, respectively. A comparison between the 5'-UTRs of AfuPV-1A dsRNAs 1, 2 and 3 illustrated that they differed in length but showed some conserved nucleotides at the 5' terminus (CGC/AAAAA/UG/U; Fig. 1d). This is consistent with observations for multi-component RNA viruses, where the 5'-terminal sequences are essential for recognition by the viral RdRP during viral RNA replication [6]. Such conserved sequences proximal to the 5'termini of partitiviruses are thought to be involved in RdRP recognition for RNA packaging and/or replication [17]. The 3'-UTRs differ in length, and there is little sequence conservation (Fig. 1d). In silico analysis of the entire sequence of AfuPV1A dsRNA3, including both UTRs, revealed the presence of stem-loop and panhandle structures (results not shown), but their significance in replication is unknown [17]. It is not known why some members of the family Partitiviridae possess a bipartite genome while others appear to be tripartite, as is the case now for AfuPV-1A. It is curious that the smallest dsRNA element was not isolated in our initial screens of dsRNA elements in A. fumigatus, but the appearance and 
disappearance of mycovirus elements in some instances is thought to be related to fungal growth conditions and variable virus distribution in mycelia. In the absence of reverse genetics to investigate whether AfuPV-1A dsRNA3 and similar dsRNAs in other partitiviruses are essential, any possible roles in replication remain unknown.

Acknowledgements The authors thank S. Greengo, M. Martinez and H. Nazik for assistance; R. Moss and L. Tell for providing A. fumigatus isolates.

Open Access This article is licensed under a Creative Commons Attribution 4.0 International License, which permits use, sharing, adaptation, distribution and reproduction in any medium or format, as long as you give appropriate credit to the original author(s) and the source, provide a link to the Creative Commons licence, and indicate if changes were made. The images or other third party material in this article are included in the article's Creative Commons licence, unless indicated otherwise in a credit line to the material. If material is not included in the article's Creative Commons licence and your intended use is not permitted by statutory regulation or exceeds the permitted use, you will need to obtain permission directly from the copyright holder. To view a copy of this licence, visit http://creativecommons.org/licenses/by/4.0/.

\section{References}

1. Altschul SF, Madden TL, Schaffer AA, Zhang J, Zhang Z, Miller W, Lipman DJ (1997) Gapped BLAST and PSI-BLAST: a new generation of protein database search programs. Nucleic Acids Res 25:3389-3402

2. Bhatti MF, Bignell EM, Coutts RHA (2011) Complete nucleotide sequences of two dsRNAs associated with a new partitivirus infecting Aspergillus fumigatus. Arch Virol 156:1677-1680

3. Botella L, Tuomivirta TT, Hantula J, Diez JJ, Jankovsky L (2015) The European race of Gremmeniella abietina hosts a single species of Gammapartitivirus showing a global distribution and possible recombinant events in its history. Fungal Biol 119:125-135

4. Coutts RHA, Livieratos IC (2003) A rapid method for sequencing the 5'- and 3'-termini of dsRNA viral templates using RLM RACE. J Phytopathol 151:525-527

5. Froussard P (1992) A random-PCR method (rPCR) to construct whole cDNA library from low amounts of RNA. Nucleic Acids Res 20:2900

6. Jiang Y, Wang J, Yang B, Wang Q, Zhou J, Yu W (2019) Molecular characterization of a debilitation-associated partitivirus
Infecting the pathogenic fungus Aspergillus flavus (2019). Front Microbiol. https://doi.org/10.3389/fmicb.2019.00626

7. Jiang Y, Luo C, Jiang D, Li G, Huang J (2014) The complete genomic sequence of a second novel partitivirus infecting Ustilaginoidea virens. Arch Virol 159:1865-1868

8. Kotta-Loizou I, Coutts RHA (2017) Mycoviruses in Aspergilli: a comprehensive review. Front Microbiol 8:1699

9. Kotta-Loizou I, Coutts RHA (2017) Studies on the virome of the entomopathogenic fungus Beauveria bassiana reveal novel dsRNA elements and mild hypervirulence. PLoS Pathog 13:e1006183

10. Liu W, Duns G, Chen J (2005) Genomic characterization of a novel partitivirus infecting Aspergillus ochraceus. Virus Genes 37:322-327

11. Nerva L, Forgia M, Ciuffo M, Chitarra W, Chiapello M, Vallino M, Varese GC, Turina M (2019) The mycovirome of a fungal collection from the sea cucumber Holothuria polii. Virus Res 273:197737

12. Sabino R, Veríssimo C, Parada H, Brandão J, Viegas C, Carolino E, Clemons KV, Stevens DA (2014) Molecular screening of 246 Portuguese Aspergillus isolates among different clinical and environmental sources. Med Mycol 52:519-529

13. Sabino R, Ferreira JA, Moss RB, Valente J, Veríssimo C, Carolino E, Clemons KV, Everson C, Banaei N, Penner J, Stevens DA (2015) Molecular epidemiology of Aspergillus collected from cystic fibrosis patients. J Cyst Fibros 14:474-481

14. Sabino R, Burco J, Valente J, Veríssimo C, Clemons KV, Stevens DA, Tell LA (2019) Molecular identification of clinical and environmental avian Aspergillus isolates. Arch Microbiol 201:253-257

15. Tuomivirta TT, Hantula J (2003) Two unrelated double-stranded RNA molecule patterns in Gremmeniella abietina type A code for putative viruses of the families Totiviridae and Partitiviridae. Arch Virol 148:2293-2305

16. Tuomivirta TT, Hantula J (2005) Three unrelated viruses occur in a single isolate of Gremmeniella abietina var. abietina type A. Virus Res 110:31-39

17. Vainio EJ, Chiba S, Ghabrial SA, Maiss E, Roossinck M, Sabanadzovic S, Suzuki N, Xie J, Nibert M (2018) ICTV virus taxonomy profile: Partitiviridae. J Gen Virol 99:17-18

18. Zhang T, Jiang Y, Huang J, Dong W (2013) Genomic organization of a novel partitivirus from the phytopathogenic fungus Ustilaginoidea virens. Arch Virol 158:2415-2416

Publisher's Note Springer Nature remains neutral with regard to jurisdictional claims in published maps and institutional affiliations. 